\title{
Technè
}

La science au service de l'histoire de l'art et de la préservation des biens culturels

$43 \mid 2016$

Une Europe de la recherche en sciences du patrimoine

\section{Applications of neutron-based and ion beam methods in Cultural Heritage research at the Budapest Neutron Centre}

Applications des méthodes neutroniques et à faisceaux d'ions dans l'étude du patrimoine culturel au centre de neutrons de Budapest

Zsolt Kasztovszky, Zoltán Kis, Boglárka Maróti, László Szentmiklósi, Györg Káli, Imre Kovács, Adél Len, Katalin Pánczél-Bajnok, László Rosta and Zoltán Szőkefalvi-Nagy

\section{(2) OpenEdition}

\section{Journals}

Electronic version

URL: http://journals.openedition.org/techne/701

DOI: 10.4000/techne.701

ISSN: 2534-5168

Publisher

C2RMF

Printed version

Date of publication: 1 August 2016

Number of pages: 70-74

ISBN: 978-2-7118-6338-9

ISSN: 1254-7867

\section{Electronic reference}

Zsolt Kasztovszky, Zoltán Kis, Boglárka Maróti, László Szentmiklósi, Györg Káli, Imre Kovács, Adél Len, Katalin Pánczél-Bajnok, László Rosta and Zoltán Szőkefalvi-Nagy, « Applications of neutron-based and ion beam methods in Cultural Heritage research at the Budapest Neutron Centre », Technè [Online], 43 | 2016, Online since 19 December 2019, connection on 24 July 2020. URL : http:// journals.openedition.org/techne/701 ; DOI : https://doi.org/10.4000/techne.701

La revue Technè. La science au service de l'histoire de l'art et de la préservation des biens culturels est mise à disposition selon les termes de la Licence Creative Commons Attribution - Pas d'Utilisation Commerciale - Pas de Modification 4.0 International. 
Zsolt Kasztovszky

Györg Káli

Zoltán Kis

Imre Kovács

Adél Len

Boglárka Maróti

Katalin Pánczél-Bajnok

László Rosta

László Szentmiklósi

Zoltán Szókefalvi-Nagy

\section{Applications of neutron-based and ion beam methods in Cultural Heritage research at the Budapest Neutron Centre}

Abstract. Cultural Heritage experiments in synergy with neutronbased and ion beam techniques at the Budapest Neutron Centre are presented, with special emphasis to successful applications within the CHARISMA project.

Keywords. Non-destructive analysis, neutron induced analytical techniques, Prompt Gamma Activation Analysis (PGAA), neutron radiography, neutron diffraction, ion-beam analysis.
Applications des méthodes neutroniques et à faisceaux d'ions dans l'étude du patrimoine culturel au centre de neutrons de Budapest

\section{Introduction}

Interest is growing towards the preservation and characterization of tangible Cultural Heritage $(\mathrm{CH})$ artefacts both in Europe and worldwide. The systematic use of scientific tools developed originally in physics, chemistry, biology, geology, etc., have become part of a separate discipline by now, answering questions related to dating, provenance, workshop identification, as well as fake identification or preservation of valuable objects, mostly in a completely non-destructive way.

Neutrons are ideal for archaeometry because their interactions with matter offer possibility to explore the compositional or structural features of samples. Slow neutrons of relatively low flux intensities $\left(10^{7}-10^{9} \mathrm{~cm}^{-2} \mathrm{~s}^{-1}\right)$ in guided neutron beams make no damage at all to objects and the induced radioactivity decays fast. By detecting the characteristic $\gamma$-photons from capture reactions, one can determine the "bulk" elemental composition, whereas by studying elastic or inelastic neutron scattering patterns the structural properties, morphology, phase composition, mechanical strains, impurities, etc., can be revealed on atomic, molecular or nano-scale level.

The Budapest Neutron Centre ${ }^{1}$ (BNC) has a long tradition in application of neutrons for Cultural Heritage research. Its Prompt Gamma Activation Analysis (PGAA), Small Angle Neutron Scattering (SANS), Neutron Diffraction (ND), Neutron Imaging (NIPS-NORMA) facilities, as well as related techniques (e.g. external milli-beam PIXE) have been involved in domestic and European archaeological research.
Résumé. Les recherches sur le patrimoine culturel utilisant les méthodes neutroniques et à faisceaux d'ions au centre de neutrons de Budapest présentées ici mettent l'accent sur les applications fructueuses réalisées dans la cadre du programme européen CHARISMA.

Mots-clés. Analyse non-destructive, techniques d'analyse neutronique, analyse par activation nautronique du rayonnement gamma instantané, radiographie neutronique, diffraction neutronique, analyse par faisceaux d'ions.

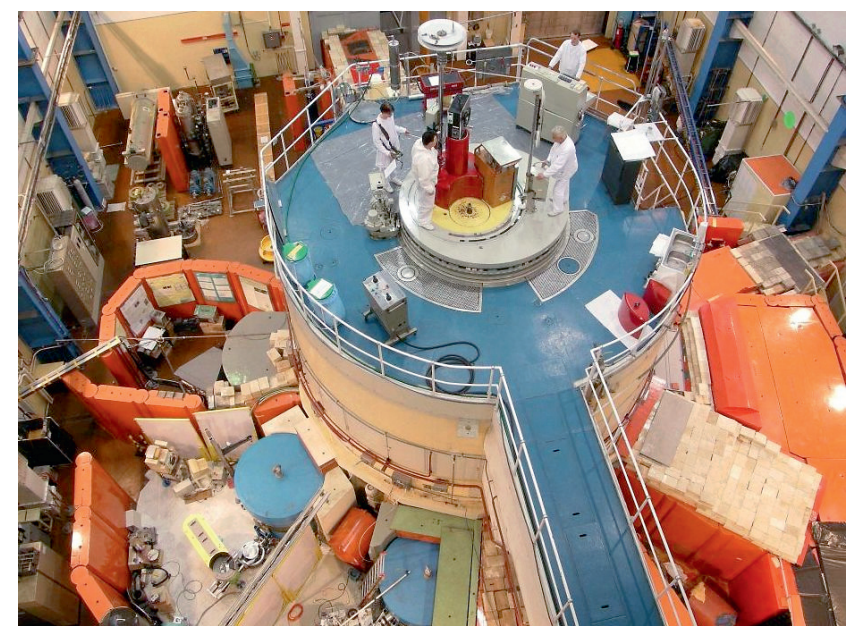

Fig. 1. Photo of the Budapest Research Reactor, experimental station used in Cultural Heritage research at BNC. () MTA EK.

Zsolt Kasztovszky (kasztovszky.zsolt@energia.mta.hu), Zoltán Kis, Boglárka Maróti, László Szentmiklósi, Hungarian Academy of Sciences (HAS) Centre for Energy Research. Györg Káli, Imre Kovács, Adél Len, Katalin Pánczél-Bajnok, László Rosta, Zoltán Szốkefalvi-Nagy, Hungarian Academy of Sciences (HAS) Wigner Research Centre for Physics. 


\section{Instrumentation and applications}

Soon after the modernisation of the 10 MW Budapest Research Reactor, the PGAA facility started to operate on a thermal neutron beam in 1995. Following the installation of a Cold Neutron Source in 2000 and other technical improvements, $10^{8} \mathrm{~cm}^{-2} \mathrm{~s}^{-1}$ neutron flux has been achieved in $2012^{3}$. PGAA is applicable to determine the "bulk" elemental composition of historical objects, made of almost any material. Since 1997, its performance in analysis of metals, rocks and minerals, ceramics and glass has been evaluated. Elemental compositions (most major components and a few traces) are determined, including dominantly stone objects and their raw materials, ceramics, metals and glass. CHARISMA also stimulated the co-operations with national and international research groups, museums. With the Hungarian National Museum, we are leading a national project focusing on prehistoric stone objects and their raw materials from Central Europe $^{4}$. Up to now, we established an analytical database containing hundreds of stone pieces made of obsidian, flint, porphyry, metabasic rocks, etc.

Two neutron-imaging facilities, RAD and NIPS-NORMA, operate at the BNC providing innovative imaging complementary to the compositional studies. The RAD station, with a large field-of-view (up to $20 \mathrm{~cm}$ ) and a massive sample manipulator, is designed to study large objects. It can perform both neutron and X-ray imaging ${ }^{5}$, to provide complementary information on the inner, often invisible structure of an object $^{6}$. The RAD station now offers a new digital imaging system to acquire detailed 2D and 3D images.

At the NIPS-NORMA station, local element composition and visual information can be alongside obtained by combining position-sensitive PGAA and neutron radiography/tomography $(\mathrm{NR} / \mathrm{NT})$ into a unique facility ${ }^{7}$. With collimated neutron beam and gamma detection, 2D or 3D distribution of elements can be determined by acquisition of gamma spectra at different positions. This technique is called Prompt Gamma Activation Imaging (PGAI). The system operates routinely, and is involved in $\mathrm{CH}$ projects since 2012. The neutron-based imaging and PGAI methods could answer questions e.g. in porous $\mathrm{CH}$ materials, corrosion processes in metals. In an experiment, proposed within the CHARISMA, the longitudinal distribution of $\mathrm{Cl}$ in archaeological iron nails could be linked to the visible damage to the corrosion layers and attack of the iron core ${ }^{8}$.

At the upgraded NAA laboratory, accurate multi-elemental panoramic analysis can be done in environmental monitoring, geochemistry, as well as archaeometry. A few tens of milligrams of samples can be irradiated in $5.3 \times 10^{13} \mathrm{~cm}^{-2} \mathrm{~s}^{-1}$ flux, and 35-75 elements can be determined, following the short- and long-time irradiations ${ }^{9}$.

A high resolution time-of-flight powder diffractometer (TOF-ND), operated by Wigner RCP, is installed on a thermal neutron beam in a separate guide-hall. In high resolution mode, the short $(10 \mu \mathrm{s})$ neutron pulse and the $25 \mathrm{~m}$ total flight path provide a neutron diffractogram with a $1.5 \times 10^{-3} \AA$ accuracy in a single measurement; the maximum beam size is $25 \times 100 \mathrm{~mm}^{2}$. During an upgrade in 2014 , the high angle detector has been changed to a large detector bank consisting of 84 single ${ }^{3} \mathrm{He}$ tubes and a sample-stage mechanism for large and heavy objects, especially for delicate art- and archaeological objects.

TOF-ND is applied for structural analysis of multiphase alloys, strain analysis in structural materials. Examples of $\mathrm{CH}$ related applications: Compositions and states of alloys (as bronzes) to reveal the manufacturing technique (casting, plastic deformation); comparison of different (European and eastern) forging techniques, identification of the origin of the objects; analyses of highly corroded iron artefacts for residual metal content ${ }^{10}$.

The SANS diffractometer is installed on a curved cold neutron guide, made of supermirrors, with $4 \times 4 \mathrm{~cm}^{2}$ crosssection. The beam is monochromatised by a mechanical velocity selector of 700 to $7000 \mathrm{~min}^{-1}$ (wavelengths can be tuned between 3 and $25 \AA$ ). It covers a momentum transfer range that allows probing structures at length scales from $5 \AA$ to $1400 \AA^{11}$.

SANS can be applied to study chemical aggregation, defects in materials, ferromagnetism, magnetic correlations, alloy segregation, as well as various biological materials. From the field of $\mathrm{CH}$, for example, several 19th and 20th century fired clay bricks have been measured. The SANS allowed to provide information on the burning conditions ${ }^{12}$. It has been also used to investigate ancient textiles from pre-dynastic and Ptolemaic ages. The primary goal of the analyses was to complete the technological description of the objects ${ }^{13}$.

An external milli-beam particle induced X-ray emission (PIXE) set-up of the Wigner $\mathrm{RCP}^{14}$ allows more comprehensive elemental analyses of $\mathrm{CH}$ objects. Millimetre sized surface regions of some tens of micrometre thick on an object of practically any size and shape can be quantitatively analysed. In standard detection conditions elements from $\mathrm{Al}$ to $\mathrm{U}$ can simultaneously be detected even with ppm sensitivities. It was proven in the CHARISMA project that the synergy of neutron techniques and PIXE significantly increases the attractiveness of $\mathrm{BNC}$ for $\mathrm{CH}$ oriented research.

\section{Highlights of the CHARISMA Transnational Access experiments performed at the $\mathrm{BNC}$}

\section{Highlight 1 - 3D Neutron Imaging of a XVIIIth Dynasty Egyptian Sealed Pottery}

User Group: Emmanuel Abraham (UGL) LOMA, UMR CNRS 5798, University of Bordeaux, FR, Marie-Christine Hervé (Museum of Aquitaine, Bordeaux, FR)

3D and 2D neutron imaging and non-destructive positionsensitive elemental analysis were performed at the Budapest Neutron Centre on a XVIIIth Dynasty (15th century BC) Egyptian sealed pottery. The result of the neutron tomography 
Fig. 2. The NIPS-NORMA station at the BNC and the investigated pottery. (C) MTA EK/E. Abraham.
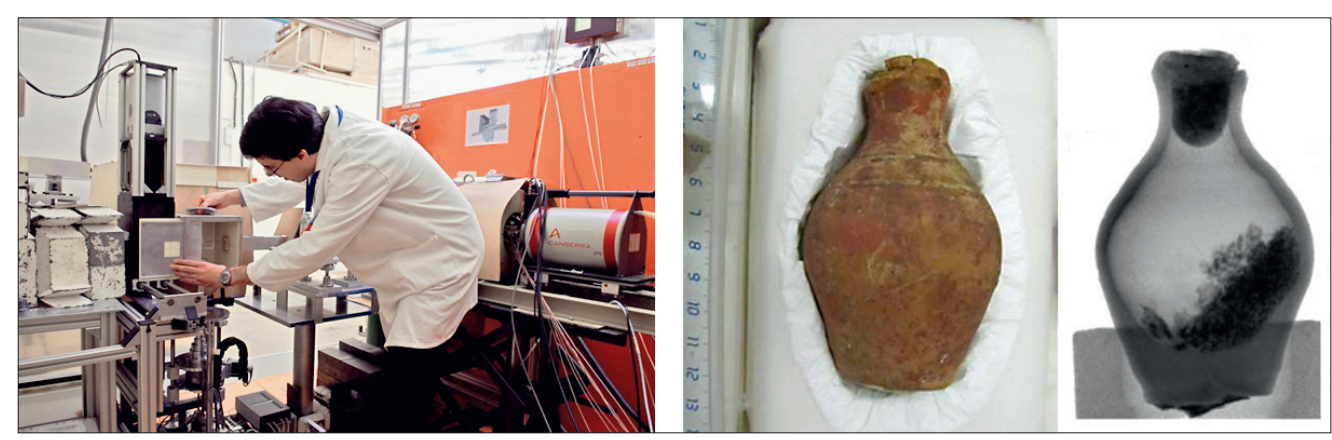

revealed that a ball of linen was most probably used to seal the jar. Furthermore, finer structural details of the inner content were made visible, which was not possible to find out in earlier attempts. With the help of highly penetrating and well collimated neutron beam, local elemental composition was determined that allowed us to conclude about the nature of the inner content, which is supposed to be a dried organic material.

The precise determination of the material composition and the substructure analysis of historic objects is a general research interest for art scientists, historians and museum curators. This scientific approach is essential as it can be employed to reveal the history of the sample, investigate the original material properties and even discover how the object has been restored in the past. In this field of cultural heritage research, we recently investigated a sealed Ancient Egyptian pottery from the XVIIIth Dynasty (New Kingdom period), stored in the Museum of Aquitaine in Bordeaux, France. The object (inventory number 8608 ) is $97 \mathrm{~mm}$ in height with a maximum diameter of $64 \mathrm{~mm}$.

The original use of this jar remains a mystery for curators. Without any specific decoration, it looks like a simple red clay vessel hermetically sealed with a clay cork. Its shape (a jar with a neck) indicates that it was most likely used for liquids and not ointment, perfumed cream, or unguent, since it would not allow easy access to these less liquid contents for skin application. However, the existence of Menkheperre Tuthmosis III's cartouche (1479-1425 BC) on the pottery's clay cork allows us to infer that this object was probably very important, perhaps linked with the funeral ritual of this pharaoh. Indeed, a sticker under the object indicates that it was purchased in 1861 in Gournah, on the famous necropolis of Thebes (on the west bank of Luxor). According to experts, this nearly 3500 -year-old pottery bottle probably did not contain viscera - usually preserved in canopic jars - but most likely offerings of food to the dead during his funeral.

The Egyptian jar was already analysed in the framework of the CHARISMA project. Previous investigations were performed by X-ray and Terahertz (THz) radiation. These first experiments revealed the presence of an unidentified content inside the object. The non-invasive $\mathrm{THz}$ transmission imaging revealed an internal mobile content inside the jar. This content was also visualized using an X-ray scanner.
The second CHARISMA project - performed at the Budapest Neutron Centre (BNC) - had two main objectives: first, the analysis of the jar to reveal any cracks in its clay body and to identify the composition of the seal; secondly, the analysis of the content unidentified by previous investigations. During the investigation complementary neutron analytical techniques were applied such as Neutron Tomography and Neutron Induced Prompt gamma Spectroscopy.

At the BNC, the jar was analysed by NIPS-NORMA instrument installed at a guided cold neutron beam, in order to determine the physical properties of the object with a complementary physical approach. The experimental setup consists of the Neutron Induced Prompt Gamma Spectrometer (NIPS), equipped with "NORMA" neutron radiography and 3D tomography system. By systematically moving the object, we were also able to create a composite 2D image of the whole jar from a set of tile images, in order to visualize its structure with a spatial resolution of $0.3 \mathrm{~mm}$ (fig. 2).

The main results are the precise identification of the cork stopper hidden by a clay cork. 3D neutron imaging clearly reveals that this stopper is made of a ball of linen or any other string-like organic material (fig. 3). This observation was not possible with both X-rays and $\mathrm{THz}$ radiation owing to insufficient spatial resolution and contrast. Neutron imaging also confirmed the presence of cracks in the wall of the pottery bottle, as already discovered with X-rays. 3D neutron imaging also provides some representations of the mobile content which is constituted of inhomogeneous dried materials.

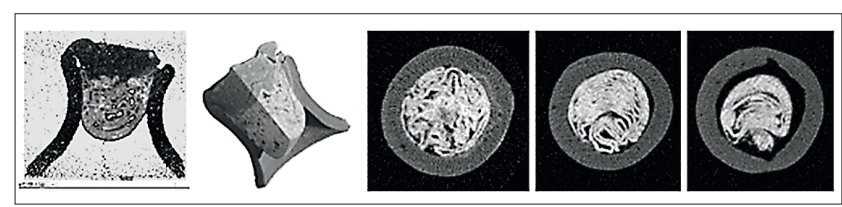

Fig. 3. 3D Neutron Imaging of the cork representing its complex structure. ( $)$ MTA EK/E. Abraham. 


\section{Highlight 2 - Quantitative Analysis and Distribution of Chloride in Archaeological Iron}

User group: Prof. D. Watkinson (UGL), Dr. M. Rimmer (Cardiff University, UK).

Archaeological iron objects corrode rapidly after excavation, and this is a function of their chloride ion content and the relative humidity. Quantitative measurement of this process and its effect on the physical integrity and longevity of the objects is vital to allow museums and other heritage organisations to develop management and treatment strategies for their collections. Cardiff University is currently running a 3 years AHRC/EPSRC research project that is investigating the relationships between relative humidity, chloride content, corrosion rate (measured by oxygen consumption) and physical damage to iron objects.

Currently available techniques for measuring the chloride content of the objects are destructive and provide only bulk data. The use of non-destructive neutron techniques provides the first opportunity to detect the effect of spatial distribution of chloride ions on the physical damage of objects, which is visible on the surface as cracking, lamination and loss of corrosion layers. It may be that corrosion rates and patterns of physical damage differ according to whether chloride is localised or more evenly distributed across the object.

Roman nails from two sites were analysed both as whole objects, to provide bulk chloride content through PGAA, and using the NIPS facility, in incremental sections down the length of the objects, with a slice width of $3 \mathrm{~mm}$. Corrosion rate of the objects had been previously measured at controlled relative humidity. The physical damage to objects was recorded by photographic images and X-ray radiography. Chloride concentration was high where there was significant mineralisation of the iron core and increased damage to the overlying corrosion layers (fig. 4). Bulk chloride data determined by

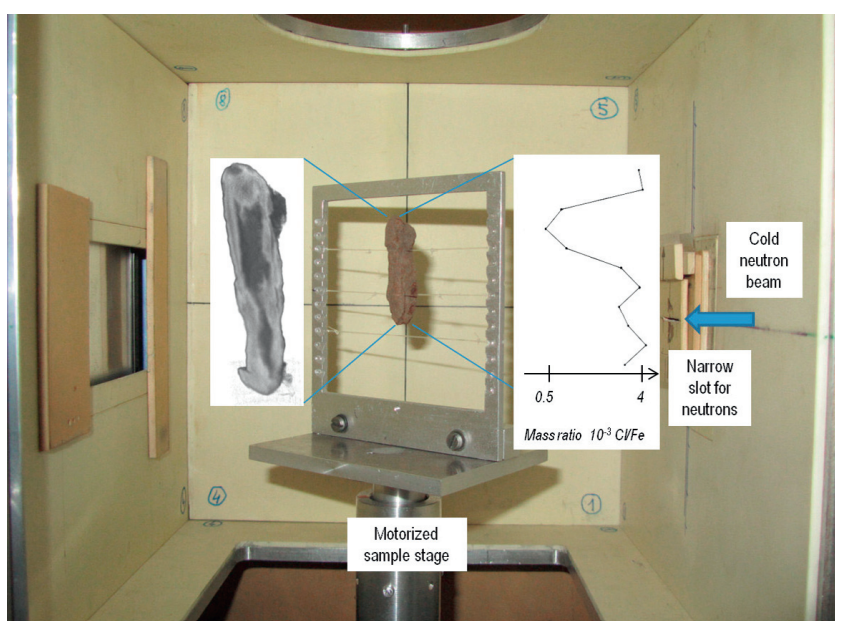

Fig. 4. Neutron tomography and NIPS analysis of iron nail CPF08_062. Eleven $3 \mathrm{~mm}$ slices were analysed, the position of each shown by the neutron radiograph and the $\mathrm{Cl} / \mathrm{Fe}$ ratios were determined. @ MTA EK/D. Watkinson.

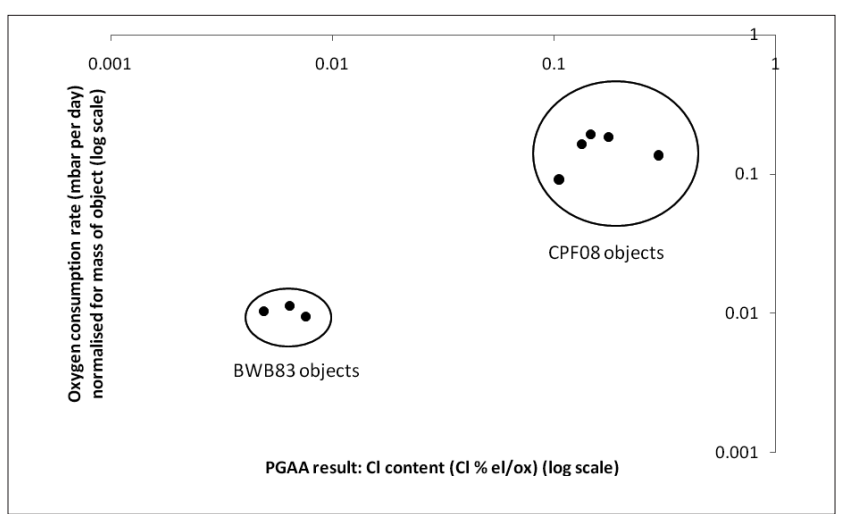

Fig. 5. Relationship between chloride content of objects, as measured by PGAA, and their corrosion rate measured by oxygen consumption. The objects from the two sites are clearly distinguished on a logarithmic scale. Slow corrosion correlates with low chloride content (BWB83 objects), while higher chloride contents correlate with faster corrosion (CPF08).

PGAA correlated well with the measured corrosion rate of objects (fig. 5), clearly distinguishing the objects from the two sites. 3D neutron tomography was also successfully trialled as a method of detailing the internal structure of corrosion layers and the metal core.

\section{Conclusion}

During the four years of the CHARISMA project, more than forty projects have been completed. The distribution of the CHARISMA projects, according to the investigated archaeological material, can be seen on the figure 6 .

The above examples clearly demonstrate the fitness of neutrons when essential analytical or structural information are requested in order to obtain pure archaeological information (provenance, workshop, trade routes, etc.). The large penetration depth to study bulk features of artefacts and the non-destructive nature of neutron techniques provide us invaluable new knowledge about ancient objects, technologies, and lifestyle - our history.

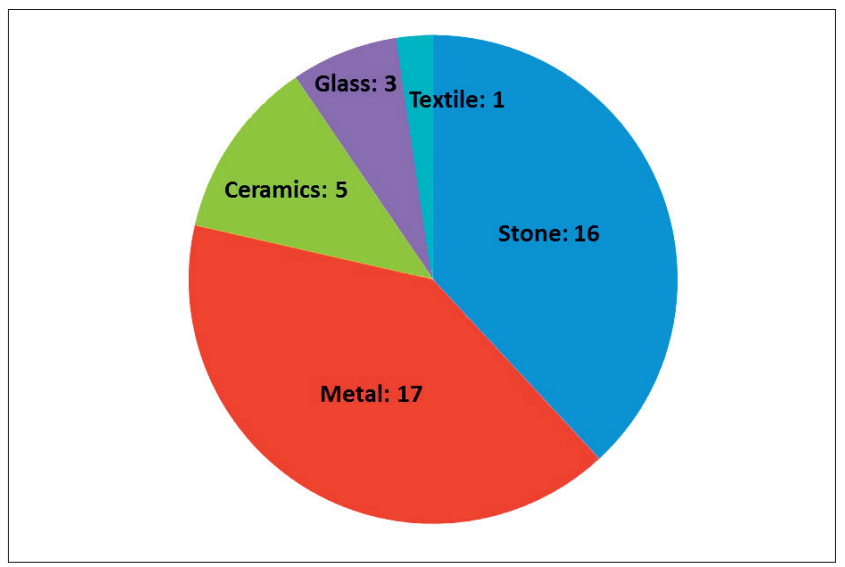

Fig. 6. The distribution of the CHARISMA projects, according to the investigated archaeological material. 


\section{Notes}

1. The Budapest Neutron Centre

(BNC) is an association of laboratories operated by the Centre for Energy Research, Hungarian Academy of Sciences and by the Wigner Research Centre for Physics, Hungarian Academy of Sciences.

2. CHARISMA webpage:

http://www.charismaproject.eu.

3. Szentmiklósi et al., 2010.

4. Kasztovszky et al., 2008.

5. Kis et al., 2015.

6. Abraham et al., 2014.

7. Kis et al., 2015.

8. Watkinson et al., 2014.

9. Gméling et al., 2014.

10. Rehren et al., 2013.

11. Rétfalvi et al., 2011.

$\mathrm{CH}$.

12. BNC Proposal number: BRR 331

13. CERIC Proposal number: 20142018.

14. Constantinescu et al., 2014.

\section{Bibliography}

Abraham E., Bessou M., Ziéglé A., Hervé M.-C., Szentmiklósi L., Kasztovszky Zs., Kis Z., Menu M., Terahertz, 2014, "X-ray and neutron computed tomography of an Eighteenth Dynasty Egyptian sealed pottery", Appl. Phys. A, p. 963-972.

Constantinescu B., Cristea-Stan D., Kovács I., Szôkefalvi-Nagy Z., 2014, "Provenance studies of Central European Neolithic obsidians using external beam milliPIXE spectroscopy", Nuclear Instruments and Methods B 318, p. 145-148.

Gméling K., Simonits A., Sziklai László I., Párkányi D., 2014, "Comparative PGAA and NAA results of geological samples and standards", Journal of Radioanalitical and Nuclear Chemistry 300, p. 507-516.

Kasztovszky Zs., Biró K. T., Markó A., Dobosi V., 2008, "Cold neutron prompt gamma activation analysis - a non-destructive method for characterisation of high silica content chipped stone tools and raw materials", Archaeometry, 50, 1, p. 12-29.

Kis Z., Szentmiklósi L., Belgya T., Balaskó M., Horváth L. Z., Maróti B., 2015 , "Neutron Based Imaging and Elementmapping at the Budapest Neutron Centre", Physics Procedia, 69, p. 40-47.

Kis Z., Szentmiklósi L., Belgya T., 2015, "NIPS-NORMA station - a combined facility for neutron-based nondestructive element analysis and imaging at the Budapest Neutron Centre", Nuclear Instruments and Methods in Physics Research A, 779, p. 116-123.

Rehren T., Belgya T., Jambon A., Káli G., Kasztovszky Z., Kis Z., Kovács I., Maróti B., Martinón-Torres M., Miniaci G., Pigott V. C., Radivojević M., Rosta L., Szentmiklósi L., Szốkefalvi-Nagy Z., 2013, "5,000 years old Egyptian iron beads made from hammered meteoritic iron”, Journal Of Archaeological Science, 40:(12), p. 4785-4792.

Rétfalvi E., Almásy L., Török Gy., Len A., Rosta L., 2001, "The small angle neutron scattering spectrometer at the Budapest Research Reactor", in J. Füzi and L. Rosta (eds.), Proc. International Workshop on New Opportunities in Single Crystal Spectroscopy with Neutrons, Révfülöp, Hungary, p. 77-78.

Szentmiklósi L., Belgya T., Révay Zs., Kis Z., 2010, "Upgrade of the prompt gamma activation analysis and the neutroninduced prompt gamma spectroscopy facilities at the Budapest Research Reactor", Journal of Radioanalitical and Nuclear Chemistry, 286, p. 501-505.

Watkinson D., Rimmer M., Kasztovszky Zs., Kis Z., Maróti B., Szentmiklósi L., 2014, "The use of neutron analysis techniques for detecting the concentration and distribution of chloride ions in archaeological iron", Archaeometry, 56, 5, p. 841-859. 